\title{
A Política de Patentes Estimula a Inovação? - o Caso da Doença de Chagas ${ }^{1}$
}

\author{
Does Patent Policy Foster Innovation? - the Case of \\ Chagas Disease
}

\section{¿La Política de Patentes Estimula la Innovación? - El Caso de la Enfermedad de Chagas}

\author{
Marcos Vinício Chein Feres \\ Anderson Resende Morais* \\ Andressa Mendes de Souza ${ }^{* * *}$
}

1 Introdução. 2 Referencial teórico. 3 Metodologia. 3.1 Estratégias metodológicas utilizadas. 3.2 Escolha da doença. 3.3 Coleta de dados. 3.4 Codificação das informações. 4 Quem são os depositante(s) nacionais dos processos de patente relacionados à doença de Chagas?. 5 Conclusão. Referências.

\section{RESUMO}

Objetivo: A doença de Chagas é uma enfermidade tropical causada pelo parasita Trypanosoma cruzi, sendo considerada negligenciada pela Organização Mundial da Saúde (OMS). Atualmente, estima-se que 1,9 a 4,6 milhões de pessoas estão infectadas por tal parasita no Brasil. No entanto, apesar dos números alarmantes, pouquíssimos são os

1 Fonte de financiamento: Este trabalho possui financiamento da Fundação de Amparo à Pesquisa de Minas Gerais (FAPEMIG) e do Conselho Nacional de Desenvolvimento Científico e Tecnológico (CNPq).

Doutor em Direito Econômico, Professor titular da Universidade Federal de Juiz de Fora (UFJF), Professor do corpo permanente do Programa de Pós-Graduação Estrito Senso em Direito e Inovação da Faculdade de Direito da UFJF, Professor colaborador no Programa de Pós-Graduação Estrito Senso em Direito da Universidade do Estado do Rio de Janeiro (UERJ) e bolsista de Produtividade PQ-2 do CNPQ. Universidade Federal de Juiz de Fora, Juiz de Fora - MG - BR. E-mail: <mvchein@gmail.com>. http://orcid.org/0000-0001-5045-3436

** Mestrando em Direito e Inovação e bolsista de pós-graduação da Universidade Federal de Juiz de Fora (UFJF). Universidade Federal de Juiz de Fora, Juiz de Fora - MG - BR. E-mail: <andersonresende.arm@gmail.com>. https://orcid.org/0000-0002-0603-5859

${ }^{* * *}$ Mestranda em Direito e Inovação pela Universidade Federal de Juiz de Fora (UFJF). Universidade Federal de Juiz de Fora, Juiz de Fora - MG - BR. E-mail: <souza.andressamendes@gmail.com>. 
tratamentos disponíveis para a referida enfermidade. Considerando que o alvo da política de propriedade intelectual deve ser o estímulo à inovação e ao desenvolvimento tecnológico, o objetivo desta pesquisa é verificar se o sistema institucional de patentes pode estar contribuindo para fomentar a pesquisa e o desenvolvimento de produtos médicos para a doença de Chagas.

Metodologias: A presente pesquisa empírica emprega uma abordagem metodológica, com base nas regras de inferências, elaboradas por Epstein e King (2013), e na codificação dos dados, proposta por Charmaz (2014), utilizando a teoria enraizada nos dados.

Resultados: Verificou-se que o sistema jurídico de patentes, em nível nacional, parece distanciar-se de seu objetivo originário, no que concerne ao desenvolvimento de produtos para prevenção e/ou cura da doença de Chagas pelo setor privado.

Contribuições: A contribuição mais relevante é a participação de instituições públicas no processo de patenteamento referente à doença de Chagas, o que corrobora a noção de que essas organizações assumem a função de instrumentos de política econômica quando aliam o desenvolvimento científico ao interesse social no que concerne à tentativa de desenvolvimento de produtos médicos voltados para a população afetada pela enfermidade.

Palavras-chave: Pesquisa Empírica em Direito. Propriedade Intelectual. Patentes. Doença de Chagas.

\section{ABSTRACT}

Objective: Chagas disease is a tropical disease caused by the parasite Trypanosoma cruzi, being considered neglected by the World Health Organization (WHO). Currently, it is estimated that 1.9 to 4.6 million people are infected with this parasite in Brazil. However, despite the alarming numbers, very few treatments are available for this disease. Considering that the aim of the intellectual property policy must be to stimulate innovation and technological development, the objective of this research is to verify whether the institutional system of patents may be contributing to foster research and development of medical products for Chagas disease.

Methodologies: This empirical research carries out a methodological approach, based on the rules of inferences, developed by Epstein and King (2013) and on the data coding, proposed by Charmaz (2014), utilizing the grounded theory.

Results: The main result is that the legal patent system, at national level, seems to distance itself from its original objective, concerning the development of products for the prevention and / or cure of Chagas disease by the private sector.

Contributions: The most relevant contribution is the participation of public institutions in the patenting process related to Chagas disease, which corroborates the notion that 
these organizations assume the role of economic policy instruments as scientific development is combined with social interest as far as the attempt to develop medical products for the population affected by the disease is concerned.

Keywords: Empirical Legal Research. Intellectual Property. Patents. Chagas disease.

\section{RESUMEN}

Objetivo: La enfermedad de Chagas es una enfermedad tropical causada por el parásito Trypanosoma cruzi, considerada desatendida por la Organización Mundial de la Salud (OMS). Actualmente, se estima que entre 1,9 y 4,6 millones de personas están infectadas con este parásito en Brasil. Sin embargo, a pesar de las cifras alarmantes, hay muy pocos tratamientos disponibles para esta enfermedad. Considerando que el objetivo de la política de propiedad intelectual debe ser estimular la innovación y el desarrollo tecnológico, el objetivo de esta investigación es verificar si el sistema institucional de patentes puede estar contribuyendo a fomentar la investigación y el desarrollo de productos médicos para la enfermedad de Chagas.

Metodologías: Esta investigación empírica se vale de un enfoque metodológico, basado en las reglas de inferencia, desarrolladas por Epstein y King (2013) y en la codificación de datos, propuesta por Charmaz (2014), se utilizando de la teoría arraigada en los datos.

Resultados: Se encontró que el sistema legal de patentes, a nivel nacional, parece distanciarse de su objetivo original, en cuanto al desarrollo de productos para la prevención y / o curación de la enfermedad de Chagas por parte del sector privado.

Contribuciones: El aporte más relevante es la participación de las instituciones públicas en el proceso de patentamiento relacionado con la enfermedad de Chagas, lo que corrobora la noción de que estas organizaciones asumen el rol de instrumentos de política económica cuando combinan el desarrollo científico con el interés social en lo que concierne el intento de desarrollar productos médicos dirigidos a la población afectada por la enfermedad.

Palabras clave: Investigación empírica en derecho. Propiedad Intelectual. Patentes. La enfermedad de Chagas.

\section{INTRODUÇÃO}

O mal de Chagas ou doença de Chagas afeta, em grande parte, populações que habitam as regiões dos trópicos do planeta Terra. É transmissivel pelo parasita Trypanosoma cruzi, por meio do inseto conhecido como barbeiro (DNDi, 2019). Por acometer pessoas que não representam um mercado suficientemente lucrativo para indústria farmacêutica privada, a doença de Chagas é considerada uma doença negligenciada pela World Health Organization (WHO, 2018). Segundo a Who (2018), 
doenças negligenciadas é um termo usado para nomear um conjunto de diferentes enfermidades transmissíveis que atingem, na maior parte dos casos, populações muito empobrecidas no mundo. Geralmente, em razão de a maioria dos infectados por esse grupo de doenças não apresentar renda elevada e, por conseguinte, não representar um mercado consumidor lucrativo, tais enfermidades recebem, por parte da indústria farmacêutica, pouco investimento em pesquisa e desenvolvimento (P\&D) de fármacos e produtos em geral.

De acordo com o mais recente relatório dos Médicos Sem Fronteiras (MÉDECINS SANS FRONTIÈRES, 2021), as políticas e os financiamentos necessários para o combate às doenças negligenciadas tendem a ser diretamente afetados por catástrofes naturais, crises humanitárias e processos migratórios, quando esses recursos econômicos são redirecionados a situações emergenciais, criando obstáculos ao bom desenvolvimento de processos e métodos de tratamento das doenças negligenciadas. $\mathrm{O}$ mesmo relatório alerta que a pandemia da Covid-19 já começa a gerar efeitos negativos para o financiamento de diagnósticos e tratamentos de doenças negligenciadas (MÉDECINS SANS FRONTIÈRES, 2021).

No momento atual, o Ministério da Saúde (BRASIL, 2019a) estima que existem por volta de 12 milhões de indivíduos acometidos pela doença de Chagas, em sua forma crônica, nas Américas. Também, ainda que não haja dados consolidados referentes ao predomínio da doença no Brasil, em estudos mais atuais do Ministério da Saúde (BRASIL, 2019a), é possivel estimar que aproximadamente 1,9 a 4,6 milhões de pessoas estão infectadas pelo Trypanosoma cruzi, equivalente entre 1,0\% a 2,4\% da população brasileira.

Consoante o relatório desenvolvido pelos Médicos Sem Fronteiras (MÉDECINS SANS FRONTIÈRES, 2021), de seis a sete milhões de pessoas estão infectadas com a doença de Chagas no mundo e mais de 70 milhões de pessoas estão em risco de infecção. Além disso, essa enfermidade é a doença parasitária mais comum nas Américas do Sul e Central, sendo, ainda, a principal causa de insuficiência cardíaca e morte nos países onde é endêmica. Apesar disso, cerca de $99 \%$ das pessoas infectadas com o mal de Chagas permanecem sem diagnóstico. Desse modo, a cada 1.000 pessoas infectadas com Chagas, apenas duas recebem o tratamento necessário (MÉDECINS SANS FRONTIĖRES, 2021).

Embora os dados referentes à incidência de mortes e de infectados pela doença de Chagas sejam alarmantes, ainda existem poucos tratamentos à disposição dos enfermos, conforme estudo realizado pelo grupo de pesquisa de Cruz et al. (2016). Atualmente, só existe um medicamento disponível, conhecido por benznidazol (BNZ). Outro medicamento que era comercializado, o Nifurtimox, teve seu uso cessado devido aos efeitos colaterais apresentados pelos pacientes. 
A análise citada acima mostrou ainda que, além de o BNZ ser o único tratamento disponível, tal medicamento apresenta restrições devido à baixa eficácia na fase crônica da doença de Chagas, além de demandar um longo período de tratamento (entre 30 a 60 dias) e, por conseguinte, ter uma alta taxa de abandono do tratamento, que também se encontra aliado aos efeitos colaterais causados e à ausência de composição para uso pediátrico.

Diante disso, surge a necessidade de desenvolvimento e inovação no que tange à possibilidade de prevenção e tratamento do mal de Chagas, assim como a discussão da política do sistema patentário no contexto do ordenamento jurídico nacional em relação às doenças negligenciadas, uma vez que, conforme dispõe a própria lei de propriedade industrial (BRASIL, 1996), a proteção conferida aos direitos de propriedade industrial tem como objetivo, dentre outras questões, o desenvolvimento tecnológico aliado ao interesse social do país.

Nesse sentido, a Constituição Brasileira dispõe que o desenvolvimento do país é um dos objetivos da República Federativa, sendo uma finalidade para o Estado Democrático de Direito (PALUMA; TEIXEIRA, 2019). Em outras palavras, na Resolução 41/128 da Assembleia Geral das Nações Unidas, de 4 de dezembro de 1986 (ONU, 1986), o direito ao desenvolvimento é considerado um direito inalienável do indivíduo, garantindo a participação de todos no desenvolvimento econômico, social, político e cultural do país. Nessa perspectiva, encontra-se o direito à saúde o qual deve ser prestado pelo Estado a todas as pessoas que necessitarem de qualquer prestação desse serviço, respaldado pela dignidade da pessoa humana (KOLLING; DELGADO, 2020). Para Kolling e Delgado (2020), a vida das pessoas que precisam recorrer a esses serviços deve ser amparada por meio do cumprimento integral do direito à saúde. Dessa forma, justifica-se o debate em torno dessa política do sistema jurídico de patentes e seu objetivo originário.

Além do mais, vale ressaltar, nas palavras de Correa (2007), que o sistema jurídico de patentes garante a exclusividade da exploração econômica da criação, a fim de, entre outros objetivos, estimular a inovação tecnológica. Nesse mesmo sentido, a formulação clássica da patente, conforme ensina Barbosa (2002), é um direito de exclusividade, conferido pelo Estado, para exploração de uma invenção. Assim, esse fato se encontra fundamentado também no Acordo sobre Aspectos dos Direitos de Propriedade Intelectual relacionados ao Comércio (TRIPS, sigla em inglês).

Segundo o Ministério das Relações Exteriores (BRASIL, 2019b), o TRIPs estabelece padrões mínimos de proteção a serem observados pelos Membros, com relação a direito autoral, a marcas, a indicações geográficas, a desenhos industriais, a patentes, a circuitos integrados e à informação confidencial. Esse documento incorpora os principais dispositivos substantivos da Convenção de Paris para a Proteção da Propriedade Intelectual e da Convenção de Berna para a Proteção de Trabalhos 
Literários e Artísticos (com exceção dos direitos morais), ambos negociados no âmbito da Organização Mundial da Propriedade Intelectual (OMPI), ao contrário do Acordo TRIPS que foi negociado, em 1994, no final da Rodada do Uruguai.

Feres e Silva (2017) sustentam que, dentre os objetivos almejados pelo TRIPS, em seu artigo $7^{\circ}$, é possível verificar explicitamente a aspiração do tratado em contribuir para a promoção da inovação tecnológica por meio do equilíbrio entre direitos e obrigações com o fim de promover o bem-estar social. Ressalta-se que o referido dispositivo foi incluído no ordenamento jurídico brasileiro pelo Decreto $\mathrm{n}^{\circ} 1.355$ (BRASIL, 1994b). Transcreve-se:

Artigo 7 - A proteção e a aplicação de normas de proteção dos direitos de propriedade intelectual devem contribuir para a promoção da inovação tecnológica e para a transferência e difusão de tecnologia, em benefício mútuo de produtores e usuários de conhecimento tecnológico e de uma forma conducente ao bem-estar social econômico e a um equilíbrio entre direitos e obrigações (BRASIL, 1994a, p. 5).

Assim sendo, considerando todo esse cenário, pergunta-se se o sistema jurídico de patentes estimula, em nível nacional, o desenvolvimento de produtos voltados para a doença de Chagas pelo setor privado.

Preliminarmente, afirma-se que o sistema jurídico de patentes, em nível nacional, opera a partir de uma lógica que se distancia de sua aspiração originária, no que se refere ao estímulo e ao desenvolvimento de novos produtos para doenças de Chagas pelo setor privado.

Nesse sentido, a abordagem teórico-metodológica consiste na reconstrução de um sistema analítico de conceitos, a partir da tensão entre a moralidade da aspiração e a moralidade do dever, proposta por Bankowski (2008), além das regras de inferência, elaboradas por Epstein e King (2013), e da teoria enraizada nos dados de Charmaz (2014).

\section{REFERENCIAL TEÓRICO}

O referencial teórico utilizado é composto pela interação entre a moralidade da aspiração e a moralidade do dever, de acordo com a perspectiva trazida por Bankowski (2008). Para o autor, o cumprimento de normas não deve se dar integral e isoladamente. Antes, é necessário que se compreenda a aspiração existente por detrás da regra, a fim de evitar uma atuação legalista do intérprete.

Segundo o mesmo autor, legalismo consiste em um modo de aplicação do direito de forma literal e restrita, sem levar em conta o caráter dinâmico das relações sociais. Dessa forma, no processo de interpretação e aplicação de uma regra, deve-se considerar sempre, reciprocamente, as aspirações estabelecidas quando de sua criação e os deveres 
por ela impostos. Essa ideia de aspiração desenvolvida por Bankowski tem por meta traduzir a política por trás da construção normativa, a saber, o objetivo a ser alcançado com um determinado dispositivo normativo ou mesmo todo um sistema de normas.

Nessa perspectiva, o sistema jurídico de patentes vigente não será abordado somente a partir dos deveres impostos pelas suas regras, mas de um modo que leve em considerações suas aspirações precípuas. Em vez de se considerar, única e exclusivamente, o instituto da patente como a proteção à propriedade intelectual em face da imitação por meio da exclusividade, levar-se-á em conta seus pressupostos e suas aspirações, qual seja, o incentivo ao desenvolvimento científico e tecnológico aliado ao interesse social - o fim político a ser alcançado com o sistema normativo de patentes.

Destaca-se que a aspiração do sistema jurídico de patentes no Brasil se encontra de forma explícita no texto constitucional, conforme se observa no artigo $5^{\circ}$, inciso XXIX, da Constituição Brasileira (BRASIL, 1988):

\begin{abstract}
XXIX - a lei assegurará aos autores de inventos industriais privilégio temporário para sua utilização, bem como proteção às criações industriais, à propriedade das marcas, aos nomes de empresas e a outros signos distintivos, tendo em vista o interesse social e o desenvolvimento tecnológico e econômico do País (BRASIL, 1988, online, grifo nosso).
\end{abstract}

\title{
3 METODOLOGIA
}

\subsection{ESTRATÉGIAS METODOLÓGICAS UTILIZADAS}

A fim de compreender os objetivos propostos neste estudo, é necessário esclarecer, inicialmente, o caráter empírico da presente análise. Conforme dispõe Epstein e King (2013, p. 11) “a palavra 'empírico' denota evidência sobre o mundo baseada em observação ou experiência”. Tal evidência, segundo os autores, pode ser tanto quantitativa (numérica) quanto qualitativa (não numérica), não havendo hierarquia entre elas.

Assim, diante da concepção trazida pelos autores supracitados, o que caracteriza a presente pesquisa como empírica é, justamente, o fato de ela ser baseada em dados da realidade, independentemente da natureza desses dados.

$\mathrm{Na}$ presente investigação, para alcançar os fins propostos, a estratégia metodológica utilizada será composta por elementos qualitativos, isto é, a natureza jurídica dos depositantes nacionais para doença de Chagas, e quantitativos, a saber, o número de depositantes encontrados. A partir desses elementos, será possivel desenvolver inferência descritiva, fazendo uso de fatos conhecidos para que se possa aprender sobre fatos desconhecidos. 
No que diz respeito à análise qualitativa das informações, é importante destacar, também, que a presente investigação pretende construir uma teoria partindo de um sistema analítico de conceitos, nos termos propostos por Charmaz (2014).

Segundo Charmaz (2014), a teoria fundamentada representa uma compreensão teórica abstrata da investigação empírica realizada. Assim, o estudo, com fulcro na teoria enraizada dos dados, consiste nas seguintes etapas: primeiramente, estudam-se os dados coletados a partir da investigação realizada; posteriormente, começa-se o processo de separação, classificação e sintetização dos dados, por meio da codificação qualitativa.

É importante ressaltar que, para a autora, o processo de codificação reside na elaboração e fixação de códigos a dados que descrevem cada seção oriunda da sintetização supracitada. Esse processo é importante, visto que, conforme elucida Charmaz (2014), as categorias analíticas e as relações que se traçam entre elas fornecem um controle conceitual sobre a investigação realizada.

\subsection{ESCOLHA DA DOENÇA}

Este estudo faz parte de um diagnóstico empírico mais amplo sobre os efeitos do sistema jurídico de patentes e o caso das doenças negligenciadas, no qual serão estudadas, detalhadamente, a realidade de todas essas enfermidades - definidas de acordo com a lista presente no Anexo I da Resolução no 217/2018 (INPI, 2018) do Instituto Nacional da Propriedade Industrial (INPI).

A fim de evitar qualquer viés na realização desse diagnóstico, decidiu-se também que as doenças seriam analisadas de acordo com a ordem disposta na própria resolução. Dessa maneira, a execução da referida análise obedeceria a uma lógica puramente objetiva, excluindo qualquer preferência dos pesquisadores; reduzindo-se, ao máximo, o nível de interferência humana nas escolhas realizadas.

Portanto, a doença de Chagas, por ser a primeira dessa lista, foi a escolhida como o objeto inicial desse diagnóstico e, consequentemente, da presente investigação.

\subsection{COLETA DE DADOS}

Com o objetivo de realizar um levantamento do número de depósitos nacionais de processos de patente para a doença de Chagas, aos 16 (dezesseis) dias do mês de maio de 2019, entrou-se no site oficial do INPI (INPI, 2019) e realizou-se o seguinte procedimento: ao lado esquerdo da página, na seção "serviços", clicou-se na opção "patente".

Em seguida, ao lado esquerdo da página, na subseção "patente”, clicou-se na opção "busca". Para realizar a pesquisa anonimamente, sem efetuar o login, apertou-se apenas o botão “continuar”. Na nova página, clicou-se na opção "patente”. 
Na seção destinada à pesquisa básica, especificamente no âmbito da subseção "resumo", preencheu-se o campo com a denominação aproximada ao nome da doença constante no anexo I, da Resolução no 217 de 2018 do INPI (INPI, 2018): "Chagas". Somente no caso da "doença de Chagas", optou-se por reduzir a palavra-chave ao termo "Chagas", com o intuito de se alcançar o maior número de variações possíveis, por exemplo, "mal de Chagas".

A partir desse procedimento, encontraram-se 85 processos de patente e, após a coleta e a leitura integral dos resumos dos processos, foram retirados do corpo de análise aqueles que não tinham relação com o objeto de estudo desta investigação, selecionando-se somente aqueles que estavam associados diretamente à doença de Chagas.

Assim sendo, foram excluídos: i) os processos cuja palavra-chave não correspondia à doença pesquisada e ii) os processos em que, embora a palavra-chave se referisse à doença pesquisada, a invenção não estava diretamente relacionada à doença, caso em que a menção à doença foi utilizada com outra finalidade.

Ademais, dado objetivo principal deste trabalho e dadas as dificuldades de analisar minuciosamente a forma de organização dos sistemas jurídicos alienígenas, analisaram-se somente os processos cujos depositantes eram brasileiros, excluindo-se, dessa maneira, todos aqueles que tinha um ou mais depositantes estrangeiros. Dessa forma, é possível analisar com mais profundidade e rigor as questões que envolvem a natureza jurídica dos depositantes de produtos relacionados à doença de Chagas.

\subsection{CODIFICAÇÃO DAS INFORMAÇÕES}

Finda a coleta referente aos processos de patentes, iniciou-se o procedimento de codificações das informações obtidas. Conforme esclarece Charmaz (2014), em um primeiro momento, estudaram-se os dados coletados, buscando informações acerca da natureza jurídica de cada depositante, por meio da rede mundial de computadores. Para tanto, recorreu-se às informações disponibilizadas pelo Governo Federal (BRASIL, 2019c) e pelo INPI, em sua base de dados, referente a cada depositante.

Ademais, a fim de complementar as informações citadas anteriormente, acessouse o Cadastro Nacional de Cursos e Instituições de Educação Superior Cadastro e-MEC (BRASIL, 2019c) para obter os dados acerca das Universidades encontradas.

Posteriormente, uma vez coletadas todas as informações sobre a natureza jurídica do depositante, iniciou-se o processo de separação e classificação dos dados encontrados. Essa etapa se dividiu em dois momentos: em primeiro lugar, realizou-se a codificação a partir do dado, dividindo as informações encontradas no maior número de segmentos possíveis; em seguida, realizou-se o processo de categorização, em que foram sintetizados os dados obtidos, a fim de se encontrar semelhanças entre eles. Para tanto, classificaram- 
se os resultados obtidos em 3 (três) grupos distintos, a saber, "público", no qual se encontram depositantes cujas atividades são realizadas por meio de investimento público (advindos direta ou indiretamente do governo), "privado", em que se encontram depositantes que não dependem diretamente de recursos públicos para suas atividades e "misto", composto por parcerias entre depositantes do grupo público e do grupo privado.

\section{QUEM SÃO OS DEPOSITANTE(S) NACIONAIS DOS PROCESSOS DE PATENTE RELACIONADOS À DOENÇA DE CHAGAS?}

Com a intenção de possibilitar a replicabilidade da pesquisa realizada, no Quadro 1, pode-se verificar detalhadamente a totalidade de processos de patente depositados no INPI relacionados à doença de Chagas que atendem aos critérios expostos no item anterior.

Os processos de patente estão identificados por seus respectivos números e encontram- se organizados em ordem cronológica decrescente, de acordo com as datas em que foram depositados no INPI.

Além disso, no quadro abaixo, também é possível verificar a data do depósito, o status do processo, o nome do depositante e o processo de sistematização e codificação dos dados encontrados na presente investigação, seguindo a orientação metodológica de Charmaz (2014).

Quadro 1 - Processos de patente relacionados à doença de Chagas com depositantes nacionais

\begin{tabular}{|l|l|l|l|l|l|}
\hline $\begin{array}{l}\text { Número do } \\
\text { Pedido }\end{array}$ & $\begin{array}{l}\text { Data do } \\
\text { Depósito }\end{array}$ & $\begin{array}{l}\text { Status do } \\
\text { Processo }\end{array}$ & $\begin{array}{l}\text { Nome do } \\
\text { Depositante }\end{array}$ & Código & Categoria \\
\hline $\begin{array}{l}\text { BR 10 2016 } \\
\text { 027927 5 A2 }\end{array}$ & 6 & $\begin{array}{l}\text { Em } \\
\text { andamento }\end{array}$ & $\begin{array}{l}\text { Silvio Ferreira } \\
\text { Gaglioti (BR/ES) }\end{array}$ & $\begin{array}{l}\text { Pessoa } \\
\text { Física }\end{array}$ & Privado \\
\hline $\begin{array}{l}\text { BR 10 2016 } \\
\text { 025449 3 A2 }\end{array}$ & $61 / 10 / 201$ & $\begin{array}{l}\text { Em } \\
\text { andamento }\end{array}$ & $\begin{array}{l}\text { Universidade Federal } \\
\text { de Minas Gerais } \\
\text { (BR/MG) }\end{array}$ & $\begin{array}{l}\text { Autarquia } \\
\text { de regime } \\
\text { especial }\end{array}$ & Público \\
\hline $\begin{array}{l}\text { BR 10 2016 } \\
\text { 023800 5 A2 }\end{array}$ & 6 & $\begin{array}{l}\text { Eniversidade Federal } \\
\text { de Pernambuco } \\
\text { (BR/PE) }\end{array}$ & $\begin{array}{l}\text { Autarquia } \\
\text { Federal }\end{array}$ & Público \\
\hline
\end{tabular}




\begin{tabular}{|c|c|c|c|c|c|}
\hline $\begin{array}{l}\text { BR } 102016 \\
0166160 \text { A2 }\end{array}$ & $18 / 7 / 2016$ & $\begin{array}{l}\text { Em } \\
\text { andamento }\end{array}$ & $\begin{array}{l}\text { Universidade Federal } \\
\text { de Minas Gerais } \\
(\mathrm{BR} / \mathrm{MG})\end{array}$ & $\begin{array}{l}\text { Autarquia } \\
\text { de regime } \\
\text { especial }\end{array}$ & Público \\
\hline $\begin{array}{l}\text { BR } 102016 \\
0164494 \text { A2 }\end{array}$ & $15 / 7 / 2016$ & Arquivado & $\begin{array}{l}\text { Universidade Federal } \\
\text { de Minas Gerais } \\
(\mathrm{BR} / \mathrm{MG})\end{array}$ & $\begin{array}{l}\text { Autarquia } \\
\text { de regime } \\
\text { especial }\end{array}$ & Público \\
\hline \multirow[t]{2}{*}{$\begin{array}{l}\text { BR } 102016 \\
0034086 \text { A2 }\end{array}$} & \multirow[t]{2}{*}{$18 / 2 / 2016$} & \multirow[t]{2}{*}{$\begin{array}{l}\text { Em } \\
\text { andamento }\end{array}$} & $\begin{array}{l}\text { Universidade Federal } \\
\text { de Pernambuco - } \\
\text { UFPE (BR/PE) }\end{array}$ & $\begin{array}{l}\text { Autarquia } \\
\text { Federal }\end{array}$ & \multirow[t]{2}{*}{ Público } \\
\hline & & & $\begin{array}{l}\text { Universidade Federal } \\
\text { do Vale Do São } \\
\text { Francisco-UNIVASF } \\
\text { (BR/RN) }\end{array}$ & $\begin{array}{l}\text { Fundação } \\
\text { Federal }\end{array}$ & \\
\hline $\begin{array}{l}\text { BR } 102015 \\
0284381 \text { A2 }\end{array}$ & $6 / 11 / 2015$ & $\begin{array}{l}\text { Em } \\
\text { andamento }\end{array}$ & $\begin{array}{l}\text { Universidade Federal } \\
\text { de Mato Grosso do } \\
\text { Sul (BR) }\end{array}$ & $\begin{array}{l}\text { Fundação } \\
\text { Federal }\end{array}$ & Público \\
\hline $\begin{array}{l}\text { BR } 102014 \\
0033742 \text { A2 }\end{array}$ & $13 / 2 / 2014$ & $\begin{array}{l}\text { Em } \\
\text { andamento }\end{array}$ & $\begin{array}{l}\text { Universidade Federal } \\
\text { de Ouro Preto } \\
(\mathrm{BR} / \mathrm{MG})\end{array}$ & $\begin{array}{l}\text { Fundação } \\
\text { Federal }\end{array}$ & Público \\
\hline $\begin{array}{l}\text { BR } 102013 \\
0280968 \text { A8 }\end{array}$ & $\begin{array}{l}31 / 10 / 201 \\
3\end{array}$ & $\begin{array}{l}\text { Em } \\
\text { andamento }\end{array}$ & $\begin{array}{l}\text { Universidade Federal } \\
\text { Fluminense }(\mathrm{BR} / \mathrm{RJ})\end{array}$ & $\begin{array}{l}\text { Autarquia } \\
\text { Federal }\end{array}$ & Público \\
\hline $\begin{array}{l}\text { BR } 102013 \\
0277428 \text { A2 }\end{array}$ & $\begin{array}{l}29 / 10 / 201 \\
3\end{array}$ & $\begin{array}{l}\text { Em } \\
\text { andamento }\end{array}$ & $\begin{array}{l}\text { Universidade de São } \\
\text { Paulo - USP (BR/SP) }\end{array}$ & $\begin{array}{l}\text { Autarquia } \\
\text { Estadual }\end{array}$ & Público \\
\hline \multirow[t]{2}{*}{$\begin{array}{l}\text { BR } 102013 \\
0265586 \text { A2 }\end{array}$} & \multirow[t]{2}{*}{$\begin{array}{l}15 / 10 / 201 \\
3\end{array}$} & \multirow[t]{2}{*}{$\begin{array}{l}\text { Em } \\
\text { andamento }\end{array}$} & $\begin{array}{l}\text { Universidade de São } \\
\text { Paulo - USP (BR/SP) }\end{array}$ & $\begin{array}{l}\text { Autarquia } \\
\text { Estadual }\end{array}$ & \multirow[t]{2}{*}{ Público } \\
\hline & & & $\begin{array}{l}\text { Universidade Federal } \\
\text { de Minas Gerais - } \\
\text { UFMG (BR/MG) }\end{array}$ & $\begin{array}{l}\text { Autarquia } \\
\text { de regime } \\
\text { especial }\end{array}$ & \\
\hline \multirow[t]{2}{*}{$\begin{array}{l}\text { BR } 102013 \\
0173584 \text { A2 }\end{array}$} & \multirow[t]{2}{*}{$5 / 7 / 2013$} & \multirow[t]{2}{*}{$\begin{array}{l}\text { Em } \\
\text { andamento }\end{array}$} & $\begin{array}{l}\text { Universidade Federal } \\
\text { de Minas Gerais } \\
(\mathrm{BR} / \mathrm{MG})\end{array}$ & $\begin{array}{l}\text { Autarquia } \\
\text { de regime } \\
\text { especial }\end{array}$ & \multirow[t]{2}{*}{ Público } \\
\hline & & & $\begin{array}{l}\text { Fundação de } \\
\text { Amparo à Pesquisa } \\
\text { do Estado de Minas } \\
\text { Gerais - FAPEMIG } \\
\text { (BR/MG) }\end{array}$ & $\begin{array}{l}\text { Fundação } \\
\text { Pública }\end{array}$ & \\
\hline \multirow[t]{2}{*}{$\begin{array}{l}\text { BR } 102013 \\
0173576 \text { A2 }\end{array}$} & \multirow[t]{2}{*}{$5 / 7 / 2013$} & \multirow[t]{2}{*}{$\begin{array}{l}\text { Em } \\
\text { andamento }\end{array}$} & $\begin{array}{l}\text { Universidade Federal } \\
\text { de Minas Gerais } \\
(\mathrm{BR} / \mathrm{MG})\end{array}$ & $\begin{array}{l}\text { Autarquia } \\
\text { de regime } \\
\text { especial }\end{array}$ & \multirow[t]{2}{*}{ Público } \\
\hline & & & $\begin{array}{l}\text { Fundação de } \\
\text { Amparo à Pesquisa } \\
\text { do Estado de Minas }\end{array}$ & $\begin{array}{l}\text { Fundação } \\
\text { Pública }\end{array}$ & \\
\hline
\end{tabular}




\begin{tabular}{|c|c|c|c|c|c|}
\hline & & & $\begin{array}{l}\text { Gerais - FAPEMIG } \\
\text { (BR/MG) }\end{array}$ & & \\
\hline $\begin{array}{l}\text { BR } 102013 \\
0021270 \text { A2 }\end{array}$ & $22 / 1 / 2013$ & Arquivado & $\begin{array}{l}\text { Universidade Federal } \\
\text { da Paraíba (BR/PB) }\end{array}$ & $\begin{array}{l}\text { Autarquia } \\
\text { Federal }\end{array}$ & Público \\
\hline \multirow[t]{2}{*}{$\begin{array}{l}\text { BR } 102012 \\
0279975 \text { A2 }\end{array}$} & \multirow[t]{2}{*}{$\begin{array}{l}31 / 10 / 201 \\
2\end{array}$} & \multirow[t]{2}{*}{$\begin{array}{l}\text { Em } \\
\text { andamento }\end{array}$} & $\begin{array}{l}\text { Universidade Federal } \\
\text { de Minas Gerais } \\
(\mathrm{BR} / \mathrm{MG})\end{array}$ & $\begin{array}{l}\text { Autarquia } \\
\text { de regime } \\
\text { especial }\end{array}$ & \multirow[t]{2}{*}{ Público } \\
\hline & & & $\begin{array}{l}\text { Fundação de } \\
\text { Amparo à Pesquisa } \\
\text { do Estado de Minas } \\
\text { Gerais - FAPEMIG } \\
\text { (BR/MG }\end{array}$ & $\begin{array}{l}\text { Fundação } \\
\text { Pública }\end{array}$ & \\
\hline \multirow[t]{2}{*}{$\begin{array}{l}\text { BR } 102012 \\
0190958 \text { A2 }\end{array}$} & \multirow[t]{2}{*}{$31 / 7 / 2012$} & \multirow[t]{2}{*}{$\begin{array}{l}\text { Em } \\
\text { andamento }\end{array}$} & $\begin{array}{l}\text { Universidade Federal } \\
\text { do Rio de Janeiro - } \\
\text { UFRJ (BR/RJ) }\end{array}$ & $\begin{array}{l}\text { Autarquia } \\
\text { Federal }\end{array}$ & \multirow[t]{2}{*}{ Público } \\
\hline & & & $\begin{array}{l}\text { Universidade Federal } \\
\text { de Alagoas (BR/AL) }\end{array}$ & $\begin{array}{l}\text { Autarquia } \\
\text { Federal }\end{array}$ & \\
\hline $\begin{array}{l}\text { BR } 102012 \\
0194287 \text { A2 }\end{array}$ & $27 / 6 / 2012$ & $\begin{array}{l}\text { Em } \\
\text { andamento }\end{array}$ & $\begin{array}{l}\text { Universidade Federal } \\
\text { do Rio Grande do } \\
\text { Norte (BR/RN) }\end{array}$ & $\begin{array}{l}\text { Autarquia } \\
\text { Federal }\end{array}$ & Público \\
\hline $\begin{array}{l}\text { BR } 102012 \\
0182149 \text { A2 }\end{array}$ & $21 / 6 / 2012$ & Arquivado & $\begin{array}{l}\text { Fricontel Comércio } \\
\text { de Aço Inoxidável e } \\
\text { Refrigeração LTDA- } \\
\text { EPP (BR/PA) }\end{array}$ & $\begin{array}{l}\text { Sociedade } \\
\text { Empresária }\end{array}$ & Privado \\
\hline $\begin{array}{l}\text { BR } 102012 \\
0103036 \text { A2 }\end{array}$ & $2 / 5 / 2012$ & $\begin{array}{l}\text { Em } \\
\text { andamento }\end{array}$ & $\begin{array}{l}\text { Universidade Federal } \\
\text { do Rio de Janeiro } \\
(\mathrm{BR} / \mathrm{RJ})\end{array}$ & $\begin{array}{l}\text { Autarquia } \\
\text { Federal }\end{array}$ & Público \\
\hline \multirow[t]{2}{*}{$\begin{array}{l}\text { BR } 102012 \\
0018764 \text { A8 }\end{array}$} & \multirow[t]{2}{*}{$27 / 1 / 2012$} & \multirow[t]{2}{*}{$\begin{array}{l}\text { Em } \\
\text { andamento }\end{array}$} & $\begin{array}{l}\text { Universidade Federal } \\
\text { de Minas Gerais } \\
(\mathrm{BR} / \mathrm{MG})\end{array}$ & $\begin{array}{l}\text { Autarquia } \\
\text { de regime } \\
\text { especial }\end{array}$ & \multirow[t]{2}{*}{ Público } \\
\hline & & & $\begin{array}{l}\text { Fundação de } \\
\text { Amparo à Pesquisa } \\
\text { do Estado de Minas } \\
\text { Gerais - FAPEMIG } \\
\text { (BR/MG) }\end{array}$ & $\begin{array}{l}\text { Fundação } \\
\text { Pública }\end{array}$ & \\
\hline $\begin{array}{l}\text { PI } 1104815-8 \\
\text { A2 }\end{array}$ & $\begin{array}{l}31 / 10 / 201 \\
1\end{array}$ & $\begin{array}{l}\text { Em } \\
\text { andamento }\end{array}$ & $\begin{array}{l}\text { Universidade de São } \\
\text { Paulo- USP (BR/SP) }\end{array}$ & $\begin{array}{l}\text { Autarquia } \\
\text { Estadual }\end{array}$ & Público \\
\hline \multirow[t]{2}{*}{$\begin{array}{l}\text { PI } 1106302-5 \\
\text { A2 }\end{array}$} & \multirow[t]{2}{*}{$\begin{array}{l}24 / 10 / 201 \\
1\end{array}$} & \multirow[t]{2}{*}{ Arquivado } & $\begin{array}{l}\text { Universidade Federal } \\
\text { de Ouro Preto } \\
(\mathrm{BR} / \mathrm{MG})\end{array}$ & $\begin{array}{l}\text { Fundação } \\
\text { Federal }\end{array}$ & \multirow[t]{2}{*}{ Público } \\
\hline & & & $\begin{array}{l}\text { Fundação de } \\
\text { Amparo à Pesquisa } \\
\text { de Est. de MG } \\
(\mathrm{BR} / \mathrm{MG})\end{array}$ & $\begin{array}{l}\text { Fundação } \\
\text { Pública }\end{array}$ & \\
\hline
\end{tabular}




\begin{tabular}{|c|c|c|c|c|c|}
\hline \multirow[t]{2}{*}{$\begin{array}{l}\text { PI } 1103777-6 \\
\text { A2 }\end{array}$} & \multirow[t]{2}{*}{$19 / 8 / 2011$} & \multirow[t]{2}{*}{$\begin{array}{l}\text { Em } \\
\text { andamento }\end{array}$} & $\begin{array}{l}\text { Universidade de São } \\
\text { Paulo - USP (BR/SP) }\end{array}$ & $\begin{array}{l}\text { Autarquia } \\
\text { Estadual }\end{array}$ & \multirow[t]{2}{*}{ Público } \\
\hline & & & $\begin{array}{l}\text { Fundação de } \\
\text { Amparo à Pesquisa } \\
\text { do Estado de São } \\
\text { Paulo FAPESP } \\
(\mathrm{BR} / \mathrm{SP})\end{array}$ & $\begin{array}{l}\text { Fundação } \\
\text { Pública }\end{array}$ & \\
\hline $\begin{array}{l}\text { PI } 1102567-0 \\
\text { A2 }\end{array}$ & $6 / 5 / 2011$ & $\begin{array}{l}\text { Em } \\
\text { andamento }\end{array}$ & $\begin{array}{l}\text { Centro Nacional de } \\
\text { Pesquisa em Energia } \\
\text { e Materiais (BR/SP) }\end{array}$ & $\begin{array}{l}\text { Associação } \\
\text { Privada }\end{array}$ & Privado \\
\hline \multirow[t]{3}{*}{$\begin{array}{l}\text { PI 0904827-8 } \\
\text { A2 }\end{array}$} & \multirow[t]{3}{*}{$6 / 11 / 2009$} & \multirow[t]{3}{*}{$\begin{array}{l}\text { Em } \\
\text { andamento }\end{array}$} & $\begin{array}{l}\text { Universidade Federal } \\
\text { de Uberlândia } \\
(\mathrm{BR} / \mathrm{MG})\end{array}$ & $\begin{array}{l}\text { Autarquia } \\
\text { Federal }\end{array}$ & \multirow[t]{3}{*}{ Misto } \\
\hline & & & $\begin{array}{l}\text { Fundação de } \\
\text { Amparo à Pesquisa } \\
\text { do Estado de Minas } \\
\text { Gerais (BR/MG) }\end{array}$ & $\begin{array}{l}\text { Fundação } \\
\text { Pública }\end{array}$ & \\
\hline & & & $\begin{array}{l}\text { Imunoscan } \\
\text { Engenharia } \\
\text { Molecular Ltda-Me } \\
(\mathrm{BR} / \mathrm{MG})\end{array}$ & $\begin{array}{l}\text { Sociedade } \\
\text { Empresária }\end{array}$ & \\
\hline $\begin{array}{l}\text { PI } 0903451-0 \\
\text { A2 }\end{array}$ & $27 / 8 / 2009$ & Arquivado & $\begin{array}{l}\text { Universidade Federal } \\
\text { do Piauí (BR/PI) }\end{array}$ & $\begin{array}{l}\text { Fundação } \\
\text { Federal }\end{array}$ & Público \\
\hline \multirow[t]{2}{*}{$\begin{array}{l}\text { PI 0805492-4 } \\
\text { A2 }\end{array}$} & \multirow[t]{2}{*}{$2 / 12 / 2008$} & \multirow[t]{2}{*}{$\begin{array}{l}\text { Em } \\
\text { andamento }\end{array}$} & $\begin{array}{l}\text { Fundação de } \\
\text { Amparo à Pesquisa } \\
\text { do Estado de São } \\
\text { Paulo - FAPESP } \\
(\mathrm{BR} / \mathrm{SP})\end{array}$ & $\begin{array}{l}\text { Fundação } \\
\text { Pública }\end{array}$ & \multirow[t]{2}{*}{ Público } \\
\hline & & & $\begin{array}{l}\text { Universidade de São } \\
\text { Paulo - USP (BR/SP) }\end{array}$ & $\begin{array}{l}\text { Autarquia } \\
\text { Estadual }\end{array}$ & \\
\hline $\begin{array}{l}\text { PI 0801906-1 } \\
\text { A2 }\end{array}$ & $15 / 1 / 2008$ & $\begin{array}{l}\text { Em } \\
\text { andamento }\end{array}$ & $\begin{array}{l}\text { Universidade Federal } \\
\text { de Minas Gerais } \\
(\mathrm{BR} / \mathrm{MG})\end{array}$ & $\begin{array}{l}\text { Autarquia } \\
\text { de regime } \\
\text { especial }\end{array}$ & Público \\
\hline $\begin{array}{l}\text { PI 0806285-4 } \\
\text { A2 }\end{array}$ & $15 / 1 / 2008$ & $\begin{array}{l}\text { Em } \\
\text { andamento }\end{array}$ & $\begin{array}{l}\text { Universidade Federal } \\
\text { de Minas Gerais } \\
(\mathrm{BR} / \mathrm{MG})\end{array}$ & $\begin{array}{l}\text { Autarquia } \\
\text { de regime } \\
\text { especial }\end{array}$ & Público \\
\hline $\begin{array}{l}\text { PI 0700836-8 } \\
\text { A2 }\end{array}$ & $20 / 3 / 2007$ & $\begin{array}{l}\text { Em } \\
\text { andamento }\end{array}$ & $\begin{array}{l}\text { Fundação Oswaldo } \\
\text { Cruz - FioCruz } \\
\text { (BR/RJ) }\end{array}$ & $\begin{array}{l}\text { Fundação } \\
\text { Pública }\end{array}$ & Público \\
\hline \multirow[t]{2}{*}{$\begin{array}{l}\text { PI 0700314-5 } \\
\text { A2 }\end{array}$} & \multirow[t]{2}{*}{$16 / 1 / 2007$} & \multirow[t]{2}{*}{ Arquivado } & $\begin{array}{l}\text { Marco Roberto Silva } \\
\text { de Alencastro } \\
(\mathrm{BR} / \mathrm{MS})\end{array}$ & $\begin{array}{l}\text { Pessoa } \\
\text { Física }\end{array}$ & \multirow[t]{2}{*}{ Privado } \\
\hline & & & $\begin{array}{l}\text { José Valdenor } \\
\text { Pinheiro da } \\
\text { Natividade (BR/MS) }\end{array}$ & $\begin{array}{l}\text { Pessoa } \\
\text { Física }\end{array}$ & \\
\hline
\end{tabular}




\begin{tabular}{|c|c|c|c|c|c|}
\hline $\begin{array}{l}\text { PI 0603871-9 } \\
\text { A2 }\end{array}$ & $24 / 8 / 2006$ & $\begin{array}{l}\text { Em } \\
\text { andamento }\end{array}$ & $\begin{array}{l}\text { Fundação } \\
\text { Universidade de } \\
\text { Brasília (BR/DF) } \\
\end{array}$ & $\begin{array}{l}\text { Fundação } \\
\text { Federal }\end{array}$ & Público \\
\hline $\begin{array}{l}\text { PI 0603872-7 } \\
\text { B1 }\end{array}$ & $24 / 8 / 2006$ & $\begin{array}{l}\text { Patente } \\
\text { Concedida } \\
\text { (em } \\
\text { 24/04/201 } \\
8 \text { ) }\end{array}$ & $\begin{array}{l}\text { Fundação } \\
\text { Universidade de } \\
\text { Brasília (BR/DF) }\end{array}$ & $\begin{array}{l}\text { Fundação } \\
\text { Federal }\end{array}$ & Público \\
\hline \multirow[t]{2}{*}{$\begin{array}{l}\text { PI 0502172-3 } \\
\text { A2 }\end{array}$} & \multirow[t]{2}{*}{$13 / 6 / 2005$} & \multirow[t]{2}{*}{$\begin{array}{l}\text { Em } \\
\text { andamento }\end{array}$} & $\begin{array}{l}\text { Universidade } \\
\text { Estadual de } \\
\text { Campinas - } \\
\text { UNICAMP (BR/SP) }\end{array}$ & $\begin{array}{l}\text { Autarquia } \\
\text { Estadual }\end{array}$ & \multirow[t]{2}{*}{ Público } \\
\hline & & & $\begin{array}{l}\text { Universidade de São } \\
\text { Paulo - USP (BR/SP) }\end{array}$ & $\begin{array}{l}\text { Autarquia } \\
\text { Estadual }\end{array}$ & \\
\hline $\begin{array}{l}\text { PI 0401107-4 } \\
\text { A2 }\end{array}$ & $13 / 4 / 2004$ & Arquivado & $\begin{array}{l}\text { Fundação Oswaldo } \\
\text { Cruz - FIOCRUZ } \\
\text { (BR) }\end{array}$ & $\begin{array}{l}\text { Fundação } \\
\text { Pública }\end{array}$ & Público \\
\hline $\begin{array}{l}\text { PI 0305933-2 } \\
\text { B1 }\end{array}$ & $2 / 12 / 2003$ & $\begin{array}{l}\text { Patente } \\
\text { Concedida } \\
\text { (em } \\
2 / 6 / 2015)\end{array}$ & $\begin{array}{l}\text { Fundação Oswaldo } \\
\text { Cruz (BR/RJ) }\end{array}$ & $\begin{array}{l}\text { Fundação } \\
\text { Pública }\end{array}$ & Público \\
\hline $\begin{array}{l}\text { PI 0202214-1 } \\
\text { A2 }\end{array}$ & $5 / 6 / 2002$ & Indeferido & $\begin{array}{l}\text { Fundação de } \\
\text { Amparo à Pesquisa } \\
\text { do Estado de São } \\
\text { Paulo (BR/SP) }\end{array}$ & $\begin{array}{l}\text { Fundação } \\
\text { Pública }\end{array}$ & Público \\
\hline $\begin{array}{l}\text { PI 0201237-5 } \\
\text { A8 }\end{array}$ & $25 / 3 / 2002$ & Arquivado & $\begin{array}{l}\text { Fundação de } \\
\text { Amparo à Pesquisa } \\
\text { do Estado de São } \\
\text { Paulo - FAPESP } \\
(\mathrm{BR} / \mathrm{SP})\end{array}$ & $\begin{array}{l}\text { Fundação } \\
\text { Pública }\end{array}$ & Público \\
\hline \multirow[t]{2}{*}{$\begin{array}{l}\text { PI 0000886-9 } \\
\text { A2 }\end{array}$} & \multirow[t]{2}{*}{$13 / 1 / 2000$} & \multirow[t]{2}{*}{ Arquivado } & $\begin{array}{l}\text { Fundação Oswaldo } \\
\text { Cruz (Fiocruz) } \\
(\mathrm{BR} / \mathrm{RJ})\end{array}$ & $\begin{array}{l}\text { Fundação } \\
\text { Pública }\end{array}$ & \multirow[t]{2}{*}{ Misto } \\
\hline & & & $\begin{array}{l}\text { Fundação Banco do } \\
\text { Brasil (BR/DF) }\end{array}$ & $\begin{array}{l}\text { Fundação } \\
\text { Privada }\end{array}$ & \\
\hline
\end{tabular}




\begin{tabular}{|c|c|c|c|c|c|}
\hline $\begin{array}{l}\text { PI } 9903472-7 \\
\text { A2 }\end{array}$ & $13 / 8 / 1999$ & Indeferido & $\begin{array}{l}\text { Universidade de São } \\
\text { Paulo - USP (BR/SP) }\end{array}$ & $\begin{array}{l}\text { Autarquia } \\
\text { Estadual }\end{array}$ & Público \\
\hline $\begin{array}{l}\text { PP } 1100552- \\
1 \text { B1 }\end{array}$ & $13 / 5 / 1997$ & $\begin{array}{l}\text { Patente } \\
\text { Extinta } \\
\text { (patente } \\
\text { concedida } \\
\text { em } \\
1 / 8 / 2000 \text { ) }\end{array}$ & $\begin{array}{l}\text { Fundação Oswaldo } \\
\text { Cruz (Fiocruz) } \\
(\mathrm{BR} / \mathrm{RJ})\end{array}$ & $\begin{array}{l}\text { Fundação } \\
\text { Pública }\end{array}$ & Público \\
\hline $\begin{array}{l}\text { PP } 1100553- \\
\text { O B1 }\end{array}$ & $13 / 5 / 1997$ & $\begin{array}{l}\text { Patente } \\
\text { Extinta } \\
\text { (patente } \\
\text { concedida } \\
\text { em } \\
1 / 8 / 2000 \text { ) }\end{array}$ & $\begin{array}{l}\text { Fundação Oswaldo } \\
\text { Cruz (Fiocruz) } \\
(\mathrm{BR} / \mathrm{RJ})\end{array}$ & $\begin{array}{l}\text { Fundação } \\
\text { Pública }\end{array}$ & Público \\
\hline \multirow[t]{5}{*}{$\begin{array}{l}\text { PI } 9603267-7 \\
\text { A2 }\end{array}$} & \multirow[t]{5}{*}{$2 / 8 / 1996$} & \multirow[t]{5}{*}{ Arquivado } & $\begin{array}{l}\text { Universidade Federal } \\
\text { de São Paulo } \\
(\mathrm{BR} / \mathrm{SP})\end{array}$ & $\begin{array}{l}\text { Autarquia } \\
\text { Federal }\end{array}$ & \multirow[t]{5}{*}{ Misto } \\
\hline & & & $\begin{array}{l}\text { Luiz Rodolpho Raja } \\
\text { Gabaglia Travassos } \\
\text { (BR/SP) }\end{array}$ & $\begin{array}{l}\text { Pessoa } \\
\text { Física }\end{array}$ & \\
\hline & & & $\begin{array}{l}\text { Igor Correia de } \\
\text { Almeida }(\mathrm{BR} / \mathrm{SP})\end{array}$ & $\begin{array}{l}\text { Pessoa } \\
\text { Física }\end{array}$ & \\
\hline & & & $\begin{array}{l}\text { Dimas Tadeu Covas } \\
(\mathrm{BR} / \mathrm{SP})\end{array}$ & $\begin{array}{l}\text { Pessoa } \\
\text { Física }\end{array}$ & \\
\hline & & & $\begin{array}{l}\text { Fundação } \\
\text { Hemocentro de } \\
\text { Ribeirão Preto } \\
(\mathrm{BR} / \mathrm{SP})\end{array}$ & $\begin{array}{l}\text { Fundação } \\
\text { Pública }\end{array}$ & \\
\hline $\begin{array}{l}\text { PI } 9602428-3 \\
\text { A2 }\end{array}$ & $17 / 5 / 1996$ & Arquivado & $\begin{array}{l}\text { Everaldo Gulart } \\
(\mathrm{BR} / \mathrm{SC})\end{array}$ & $\begin{array}{l}\text { Pessoa } \\
\text { Física }\end{array}$ & Privado \\
\hline $\begin{array}{l}\text { PI } 9503451-0 \\
\text { A2 }\end{array}$ & $26 / 7 / 1995$ & Arquivado & $\begin{array}{l}\text { Rodolfo Pereira } \\
\text { Mendes (BR/MG) }\end{array}$ & $\begin{array}{l}\text { Pessoa } \\
\text { Física }\end{array}$ & Privado \\
\hline \multirow[t]{3}{*}{$\begin{array}{l}\text { PI 9400950-3 } \\
\text { B1 }\end{array}$} & \multirow[t]{3}{*}{ 7/4/1994 } & \multirow{3}{*}{$\begin{array}{l}\text { Patente } \\
\text { Extinta } \\
\text { (patente } \\
\text { concedida } \\
\text { em } \\
\text { 26/6/2001 } \\
\text { ) }\end{array}$} & $\begin{array}{l}\text { Universidade Federal } \\
\text { de São Paulo - } \\
\text { UNIFESP (BR/SP) }\end{array}$ & $\begin{array}{l}\text { Autarquia } \\
\text { Federal }\end{array}$ & \multirow[t]{3}{*}{ Misto } \\
\hline & & & $\begin{array}{l}\text { Igor Correia de } \\
\text { Almeida (BR/SP) }\end{array}$ & $\begin{array}{l}\text { Pessoa } \\
\text { Física }\end{array}$ & \\
\hline & & & $\begin{array}{l}\text { Luiz Rodolpho Raja } \\
\text { Gabaglia Travassos } \\
\text { (BR/SP) }\end{array}$ & $\begin{array}{l}\text { Pessoa } \\
\text { Física }\end{array}$ & \\
\hline
\end{tabular}




\begin{tabular}{|l|l|l|l|l|l|}
\hline PI 9104287-9 & $3 / 10 / 1991$ & $\begin{array}{l}\text { Patente } \\
\text { E1 }\end{array}$ & $\begin{array}{l}\text { Universidade Federal } \\
\text { do Rinta de Janeiro - } \\
\text { (patente } \\
\text { concedida } \\
\text { em } \\
\text { UFRJ (BR/RJ) }\end{array}$ & $\begin{array}{l}\text { Autarquia } \\
\text { de Natureza } \\
\text { Especial }\end{array}$ & Público \\
& & & \\
& & & \\
& & & & \\
\hline
\end{tabular}

Fonte: elaborado pelos autores a partir da base de dados do Instituto Nacional de Propriedade Intelectual.

Conforme se observa nas informações apresentadas, em toda a história do INPI, foram realizados 47 processos de patente, cujos depositantes eram unicamente brasileiros. Do total de números apresentados, 37 processos foram protocolados por depositantes exclusivamente públicos, ou seja, mais de $75 \%$ dos processos de patente nacionais apresentados para a doença de Chagas são frutos de pesquisas desenvolvidas unicamente no âmbito das universidades e fundações públicas, consoante se analisa acima.

Entretanto, a participação do setor público não se restringe aos números supramencionados. Conforme se observa no quadro, do total de depósitos encontrados, 4 processos são oriundos de universidades públicas ou fundações públicas, em parceria com o setor privado.

Tal colaboração, segundo análise de Castro e Souza (2012), é consequência da promulgação da Lei da Inovação 10.973 (BRASIL, 2004), regulamentada pelo Decreto 9.283 (BRASIL, 2018), os quais dispõem sobre incentivos à inovação e à pesquisa científica e tecnológica no ambiente produtivo. Tais normas estimularam as parcerias entre universidades e empresas, por meio da instalação e/ou aperfeiçoamento dos núcleos de inovação tecnológica nas universidades. Esses núcleos são responsáveis pela gestão política de inovação das Instituições de Ensino Superior, pela avaliação de suas atividades de pesquisa, pelo acompanhamento do processo de transformação da criação em inovação tecnológica e pela promoção e gerenciamento das parcerias entre universidade e empresas.

Nesse cenário, cabe ressaltar as alterações promovidas pelo novo Marco Legal da Ciência, Tecnologia e Inovação no Brasil. Rauen (2016) afirma que a nova lei propôs alterações importantes em relação à redução significativa de pontos críticos de insegurança jurídica, fortalecendo ferramentas de estímulo à participação de Instituições de Pesquisa Científica e Tecnológica (ICTs) em atividades de inovação associadas ao segmento produtivo e dando mais clareza à aplicação e à operacionalização da lei.

O estudo realizado por Sales e Queiroz (2018) demonstra que a lei atual dispõe de um rol de instrumentos de estímulo dos quais as empresas e as ICTs podem se utilizar para incrementarem o desempenho em inovação, por exemplo, bônus tecnológico, incentivos fiscais, subvenção econômica, dentre outros. 
Em contrapartida, no que se refere às invenções provenientes unicamente do setor privado, foram encontrados somente 6 processos cujos depositantes eram exclusivamente nacionais, isto é, menos de $15 \%$ dos processos nacionais de patentes são advindos do setor privado.

Para a finalidade principal deste trabalho, contudo, é relevante destacar que, conquanto se tenha encontrado 10 participações do setor privado no que se refere aos depósitos para doença de Chagas, esse número não reflete a verdadeira atuação das empresas da área da saúde e o investimento delas em pesquisas para a referida doença. Isso porque, de todos os depósitos encontrados, apenas 2 são produtos desenvolvidos por entidades privadas, quais sejam, Centro Nacional de Pesquisa em Energia e Materiais (CNPEM) e Imunoscan Engenharia Molecular Ltda. - ME. Dessas duas entidades, apenas uma se constitui na forma de sociedade empresária, conforme artigo 966 do Código Civil (BRASIL, 2002).

O CNPEM é uma organização social supervisionada pelo Ministério da Ciência, Tecnologia, Inovações e Comunicações (MCTIC) cuja natureza jurídica é associação privada e, por isso, não possui fins lucrativos, conforme afirma Melchor (2019). Sua atividade econômica principal consiste em pesquisa e desenvolvimento experimental em ciências físicas e naturais, dentre elas, química, biologia, bioquímica e farmácia e sua atuação se divide em 4 eixos: "i) instalações abertas a usuários externos, ii) pesquisa e desenvolvimento in-house, iii) apoio à geração de inovação, iv) treinamento, educação e extensão." (CNPEM, 2021, online).

Já a Imunoscan Engenharia Molecular é uma microempresa cuja organização se dá por meio de sociedade limitada. Sua atividade econômica principal também se refere à pesquisa e ao desenvolvimento experimental em ciências físicas e naturais, dentre elas, química, biologia, bioquímica e farmácia (BRASIL, 2019d; IBGE, 2019). Nesse momento da pesquisa, não foi possível encontrar informações com maior grau de detalhamento acerca dos seus eixos de atuação e investimento em $P \& D$.

Tendo em vista que as invenções relacionadas ao mal de Chagas se concentram majoritariamente no âmbito público, havendo ínfima participação do setor privado, em especial das empresas da área de saúde, há indícios suficientes de que o sistema de patentes se distancia de sua aspiração originária de desenvolvimento tecnológico e científico aliado ao interesse social quando se pretende uma prática universal tanto no setor privado quanto no setor público.

Assim, pode-se inferir que o sistema jurídico de patentes parece funcionar, em nível nacional, de forma deficitária ${ }^{2}$ quanto ao desenvolvimento de produtos para doenças de Chagas por entes privados.

\footnotetext{
${ }^{2} \mathrm{O}$ propósito do estudo consiste em realizar um diagnóstico empírico sobre o sistema jurídico de patentes, a partir dos produtos jurídico-administrativos (patentes). O diagnóstico parece indicar que o sistema é deficitário, no que se refere ao caso das doenças negligenciadas e a relação com o setor
} 
A grande concentração de desenvolvimento de produtos para o mal de Chagas no setor público demonstra a necessidade de valorização das instituições públicas no Brasil. É importante considerar que, ao realizarem esse tipo de ação voltada para desenvolvimento de produtos de saúde no campo de uma doença negligenciada, elas atuam como instrumentos de política pública ${ }^{3}$. Conquanto não seja esta a atividade-fim das universidades e fundações, elas, porque compostas de uma elite científica de primeira linha, transformam-se, naturalmente, em estruturas institucionais essenciais para a realização de um fim social relevante e de uma ação política determinante, a saber, a aspiração do sistema jurídico de patentes, a busca pelo desenvolvimento científico aliado ao interesse social. As pesquisas executadas no setor público não seguem a lógica estruturante do sistema de mercado privado, mas sim se revelam abertas a campos e a áreas carentes de incremento tecnológico e científico, independentemente da possibilidade de retorno financeiro.

Nos dizeres de Feres e Silva (2018), isso ocorre porque, dentre outras razões, os argumentos utilizados pela indústria farmacêutica para tratar questões relacionadas à propriedade industrial concentram-se no resgate de investimentos. $\mathrm{O}$ pressuposto econômico orienta toda a atividade inventiva realizada por esse setor. Sendo assim, porque as doenças negligenciadas, neste caso, a doença de Chagas, atingem predominantemente populações de baixa renda, as quais não representam mercado com capacidade para oferecer retorno a esses laboratórios, não há interesse em investir nesse setor, quando o agente econômico responsável por esse tipo de ação é a indústria farmacêutica de caráter privado.

Tal posicionamento também é corroborado por Araújo (2014), o qual destaca que a baixa expectativa de retorno financeiro para investimentos em doenças consideradas negligenciadas (mercado consumidor sem poder de compra) torna tal mercado desinteressante para a indústria farmacêutica, que acaba por negligenciar a importância da criação de soluções terapêuticas direcionadas a essas enfermidades.

Além desses fatores, ressalta-se que, embora a proteção patentária vise ao estímulo à pesquisa e ao desenvolvimento, segundo expõem Oliveira, Labra e Bermudez (2006), o investimento em P\&D para a produção de medicamentos no Brasil é

privado. Essa teoria extraída dos dados apresenta duas implicações observáveis, dignas de ressalva. A primeira dela se refere à Lei 13.930, de 10 de dezembro de 2019, a qual foi criada com o propósito de incentivar a pesquisa e o desenvolvimento tecnológico para o tratamento de doenças negligenciadas (BRASIL, 2019e). Quanto à segunda implicação observável, ressalta-se a iniciativa do Projeto de Lei 4.212 , de 24 julho de 2019, com o propósito de garantir o selo de responsabilidade pública para as empresas que se dedicam a desenvolver produtos para doenças negligenciadas e servir de critérios de preferência no desempate da licitação (BRASIL, 2019f). Esses dois instrumentos normativos indicam a necessidade de suprir o déficit em pesquisa e desenvolvimento para produtos destinados às doenças negligenciadas.

${ }^{3}$ A fim de compreender a ideia de instituições e/ou institutos como instrumentos de política pública e/ou econômica, ver Souza (1999), Vaz (1992) e Feres (2004). 
insignificante. Klein, Hasenclever e Machado (2011) demonstram que as indústrias farmacêuticas nacionais investiram apenas $1,27 \%$ de sua receita líquida de venda (RLV) entre os anos de 2003 e 2005 em pesquisa e desenvolvimento.

Para Paranhos, Mercadante e Hasenclever (2020), no ano de 2014, as grandes empresas farmacêuticas nacionais (GEFNs) apresentaram um investimento superior aos anos anteriores, de aproximadamente 7\% sobre sua RLV. Esses investimentos foram atribuídos para as atividades de criação de conhecimento e acumulação de tecnologia. Com esse cenário, poder-se-ia inferir uma possível mudança de investimentos na indústria farmacêutica nacional. Todavia, o estudo realizado por Leão e Giesteira (2020), com base na Pesquisa de Inovação Tecnológica (Pintec) para o triênio de 2014 a 2017, demonstrou que os investimentos das indústrias farmacêuticas em P\&D no Brasil sofreram uma queda. Nessa pesquisa, apontou-se um investimento de aproximadamente $3 \%$ em P\&D.

Dessa forma, devido à falta de interesse em pesquisa e desenvolvimento das indústrias brasileiras, a maioria dos pesquisadores nacionais trabalha em universidades e instituições de pesquisa, ao contrário do que se pode imaginar, as grandes mentes nacionais não estão alocadas no setor privado (PONTES, 2017).

Ainda, segundo Cruz (2000), no Brasil, 73\% dos cientistas e engenheiros trabalham para instituições de Ensino Superior, como docentes em regime de dedicação exclusiva ou em regime integral, enquanto apenas $11 \%$ trabalham para empresas.

Esses fatores, somados à ausência de mercado com capacidade para oferecer retorno às empresas privadas que atuam no âmbito farmacêutico, como ocorre na doença de Chagas, fazem que a maioria dos produtos desenvolvidos para a referida enfermidade esteja concentrada no setor público.

É importante destacar que as doenças globais, como câncer, doenças cardiovasculares, doenças mentais e distúrbios neurológicos, ainda constituem o principal foco de P\&D da indústria farmacêutica. De acordo com a Interfarma (2019), o câncer e as doenças neurológicas lideram a produção das indústrias farmacêuticas no mundo. O mercado farmacêutico privado tende a despender mais recursos com essas enfermidades, dado o caráter crônico e alta complexidade delas, porque podem gerar mais retornos financeiros, em linha de princípio.

Dessa forma, o sistema global de P\&D está voltado para o desenvolvimento de medicamentos de alto preço, direcionados ao tratamento de doenças mais prevalentes em países de alta renda (MÉDECINS SANS FRONTIÈRES, 2021). Assim, doenças negligenciadas, como doença de Chagas e leishmaniose, que afetam exclusivamente pessoas nos países em desenvolvimento, pelo fato de a maioria dos pacientes ser muito pobre para arcar com os custos de qualquer tipo de tratamento, praticamente não representam nenhum mercado, estando fora do âmbito dos esforços de $P \& D$ da indústria farmacêutica e, portanto, fora do mercado farmacêutico privado. 
Segundo o mais recente relatório dos Médicos Sem Fronteiras (2021), o setor farmacêutico privado continua a não investir suficientemente para o desenvolvimento de novos métodos mais acessíveis, direcionados ao diagnóstico e tratamento para as doenças negligenciadas, investimentos que acabam sendo protagonizados pelo setor público, fontes filantrópicas e parcerias público-privadas, como a DNDi.

Desse modo, a partir das questões expostas, verifica-se que, no que diz respeito ao setor privado, o sistema jurídico de patentes não tem conseguido efetivar sua aspiração precípua, de incentivo ao desenvolvimento científico e tecnológico com base no interesse social.

Consoante Feres e Silva (2018), com relação às normas relacionadas à proteção patentária, a implementação destas no país não pode ocorrer sem que haja reflexões profundas sobre as implicações que tais institutos terão na vida em sociedade. Especialmente no que se refere aos países em desenvolvimento, como o Brasil, a legislação de patentes, no tocante aos fármacos, deve ter como foco principal o interesse social e a atenção aos objetivos das políticas de saúde e bem-estar adotadas pelo Estado.

\section{CONCLUSÃO}

A doença de Chagas é uma doença tropical causada pelo parasita Trypanosoma cruzi considerada negligenciada pela Organização Mundial da Saúde (OMS). Atualmente, estima-se que de 1,9 a 4,6 milhões de pessoas estão infectadas por tal parasita no Brasil. No entanto, apesar dos números alarmantes, pouquíssimos são os tratamentos disponíveis para a referida enfermidade.

Diante desse cenário, surgiu a necessidade de se discutir o papel que a política do sistema de patentes tem desempenhado no que se refere à doença de Chagas, uma vez que seu objetivo precípuo deveria ser o estímulo à inovação e ao desenvolvimento tecnológico, tendo em foco o interesse social.

A pergunta que guiou a presente pesquisa foi se o sistema jurídico de patentes estimula, em nível nacional, o desenvolvimento de produtos voltados para essa enfermidade pelo setor privado. A hipótese aqui trabalhada é a de que o sistema jurídico de patentes, em nível nacional, parece distanciar-se de sua aspiração originária, no que concerne ao desenvolvimento de produtos para doenças de Chagas pelo setor privado.

Para verificar tal questão, realizou-se, na base de dados oficial do INPI, um levantamento do número de processos de patente, que fossem relacionados, diretamente, à doença de Chagas e cujo depositante fosse nacional. Após essa coleta, os dados foram sistematizados e codificados, seguindo a metodologia da teoria fundamentada nos dados. 
A partir do aprendizado oriundo da observação desses dados empíricos (dados conhecidos), foi possível construir um processo inferencial descritivo, o qual resultou em novos dados sobre a realidade estudada (dados desconhecidos).

De modo geral, foi possivel concluir que as invenções relacionadas ao mal de Chagas se concentram majoritariamente no âmbito público, havendo diminuta participação do setor privado.

Além disso, verificou-se que, no que diz respeito ao setor privado, o sistema jurídico de patentes não tem conseguido efetivar sua aspiração precípua, de incentivo ao desenvolvimento científico e tecnológico com base no interesse social.

Enfim, a mais relevante confirmação acaba sendo a elevada participação de instituições públicas no processo de patenteamento referente à doença de Chagas, o que corrobora a noção de que elas assumem a função de instrumentos de política econômica quando aliam o desenvolvimento científico ao interesse social no que concerne à tentativa de desenvolvimento de produtos médicos voltados para a população afetada pela enfermidade. Enfim, instituições públicas de ensino e de pesquisa produzem conhecimentos e produtos relevantes para a sociedade brasileira.

\section{REFERÊNCIAS}

ARAÚJO, Lucas Bernardes. Do fomento à inovação às flexibilidades TRIPs: soluções viáveis para o problema da indisponibilidade de medicamentos de combate às doenças negligenciadas. 2014. 158 f. Dissertação (Mestrado) - Curso de Programa de PósGraduação, Universidade Federal de Belo Horizonte, Belo Horizonte, 2014.

BANKOWSKI, Zenon. Vivendo Plenamente a Lei: a lei do amor e o amor pela lei. Tradução Lucas Dutra Bertolozzo, Luiz Reimer Rodrigues Rieffel e Arthur Maria Ferreira Neto. Rio de Janeiro, RJ: Elsevier Campus, 2008.

BARBOSA, Denis Borges. Uma introdução à propriedade intelectual. 2. ed. Rio de Janeiro: Lumen Juris, 2002.

BRASIL. Constituição da República Federativa do Brasil de 1988. Brasília, DF: Presidência da República, 1988. Disponível em: http://www.planalto.gov.br/ccivil_03/Constituicao/Constituicaocompilado.Htm. Acesso em: 3 jul. 2019.

BRASIL. Ministério da Economia. Acordo Sobre Aspectos dos Direitos de Propriedade Intelectual Relacionados ao Comércio. 1994a. Disponível em: http://www.mdic.gov.br/index.php/comercio-exterior/negociacoes-internacionais/1885 -omc-acordos-da-omc. Acesso em: 10 jul. 2019. 
BRASIL. Decreto no 1.355, de 30 de dezembro de 1994. Promulgo a Ata Final que Incorpora os Resultados da Rodada Uruguai de Negociações Comerciais Multilaterais do Gatt. Brasília, DF: Presidência da República, 1994b. Disponível em: http://www.planalto.gov.br/Ccivil_03/Decreto/Antigos/D1355.Htm. Acesso em: 10 jul. 2019.

BRASIL. Ministério da Saúde. Doença de Chagas: o que é, causas, sintomas, tratamento e prevenção. 2019a. Disponível em: http://antigo.saude.gov.br/saude-de-a-z/doenca-dechagas. Acesso em: 3 jul. 2019.

BRASIL. Ministério das Relações Exteriores. O Acordo Trips: um panorama, 2019b. Disponível em: http://delbrasomc.itamaraty.gov.br/pt-br/acordo_trips.xml. Acesso em: 3 jul. 2019.

BRASIL. Ministério da Educação. Cadastro Nacional de Cursos e Instituições de Educação Superior. 2019c. Disponível em: http://emec.mec.gov.br/emec/nova. Acesso em: 10 jul. 2019.

BRASIL. Receita Federal. Emissão de Comprovante de Inscrição e de Situação Cadastral. 2019d. Disponível em: https://www.receita.fazenda.gov.br/PessoaJuridica/CNPJ/cnpjreva/cnpjreva_solicitacao 2.asp. Acesso em: 10 jul. 2019.

BRASIL. Lei $\mathbf{n}^{\circ}$ 13.930, de 10 de dezembro de 2019. Altera a Lei $n^{\circ} 10.332$, de 19 de dezembro de 2001, para garantir aplicação de percentual dos recursos do Programa de Fomento à Pesquisa em Saúde em atividades relacionadas ao desenvolvimento tecnológico de medicamentos, imunobiológicos, produtos para a saúde e outras modalidades terapêuticas destinados ao tratamento de doenças raras ou negligenciadas. Brasília, DF: Presidência da República, 2019e. Disponível em: http://www.planalto.gov.br/ccivil_03/_ato2019-2022/2019/lei/113930.htm. Acesso em: 16 fev. 2021.

BRASIL. Projeto de Lei no 4.212 de 24 julho de 2019. Cria o selo de Responsabilidade Pública para as empresas que investem em medicamentos para doenças negligenciadas e altera a Lei 8.666, de 21 de junho de 1993 (Lei de Licitações), para incluir critérios de preferência no desempate da licitação. Brasília, DF: Presidência da República, 2019f. Disponível em: https://legis.senado.leg.br/sdleggetter/documento?dm=7983827\&ts=1594035652714\&disposition=inline. Acesso em: 16 fev. 2021.

BRASIL. Lei $\mathbf{n}^{\circ} 9.279$ de 14 de maio de 1996. Regula direitos e obrigações relativos à propriedade industrial. Brasília, DF: Presidência da República, 1996. Disponível em: http://www.planalto.gov.br/ccivil_03/leis/19279.htm. Acesso em: 1 ago. 2020. 
BRASIL. Lei no 10.406, de 10 de janeiro de 2002. Institui o Código Civil. Brasília, DF: Presidência da República, 2002. Disponível em: http://www.planalto.gov.br/ccivil_03/leis/2002/L10406compilada.htm. Acesso em: 1 ago. 2020.

BRASIL. Lei $\mathrm{n}^{\circ}$ 10.973, de 02 de dezembro de 2004. Dispõe sobre incentivos à inovação e à pesquisa científica e tecnológica no ambiente produtivo e dá outras providências. Brasília, DF: Presidência da República, 2004. Disponível em: http://www.planalto.gov.br/ccivil_03/_ato2004-2006/2004/lei/110.973.htm. Acesso em: 10 jul. 2019.

BRASIL. Decreto $\mathrm{n}^{\circ}$ 9.283, de 07 de fevereiro de 2018. Regulamenta a Lei $\mathrm{n}^{\circ}$ 10.973, de 2 de dezembro de 2004, a Lei no 13.243 , de 11 de janeiro de 2016, o art. 24, § $3^{\circ}$, e o art. 32, § 7º da Lei no 8.666, de 21 de junho de 1993, o art. $1^{\circ}$ da Lei no 8.010, de 29 de março de 1990, e o art. 2, caput, inciso I, alínea "g", da Lei no 8.032, de 12 de abril de 1990, e altera o Decreto $\mathrm{n}^{\circ}$ 6.759, de 5 de fevereiro de 2009, para estabelecer medidas de incentivo à inovação e à pesquisa científica e tecnológica no ambiente produtivo, com vistas à capacitação tecnológica, ao alcance da autonomia tecnológica e ao desenvolvimento do sistema produtivo nacional e regional. Brasília, DF: Presidência da República, 2018. Disponível em: http://www.planalto.gov.br/ccivil_03/_Ato20152018/2018/Decreto/D9283.htm\#art83. Acesso em: 10 jul. 2019.

CASTRO, Biancca Scarpeline de; SOUZA, Gustavo Costa de. O papel dos Núcleos de Inovação Tecnológica (NITs) nas universidades brasileiras | The role of Technological Innovation Centers in Brazilian universities. Liinc em Revista, v. 8, n. 1, 2012. http://dx.doi.org/10.18617/liinc.v8i1.465. Disponível em: http://revista.ibict.br/liinc/article/view/3345. Acesso em: 10 set. 2020.

CENTRO NACIONAL DE PESQUISA EM ENERGIA E MATERIAIS CNPEM. Página inicial. Disponível em: https://cnpem.br/. Acesso em: 10 fev. 2021.

CHARMAZ, Kathy. Constructing Grounded Theory: introducing qualitative methods series. 2. ed. Londres: Sage, 2014.

CORREA, Carlos. Trade Related Aspects of Intelectual Property Rights: a comentary on the trips agreement. Oxford: Oxford University Press, 2007.

CRUZ, Carlos H. de Brito. A Universidade, a Empresa e a Pesquisa que o país precisa. Parcerias Estratégicas, Brasília, v. 5, n. 8, p. 1-27, 2000. Disponível em: http://seer.cgee.org.br/index.php/parcerias_estrategicas/article/viewFile/101/94.

Acesso em: 10 set. 2020.

CRUZ, Cleide Ane Barbosa da et al. Tecnologias que empregam fármacos antiparasitários para tratamento da doença Chagas. Revista Eletrônica de 
Comunicação, Informação e Inovação em Saúde, Rio de Janeiro, v. 10, n. 1, p.1-9, jan./mar. 2016. Disponível em: https://www.reciis.icict.fiocruz.br/index.php/reciis/article/view/1075/pdf_1075.

Acesso em: 15 ago. 2019.

DRUGS FOR NEGLECTED DISEASES INITIATIVE - DNDi. O que é a doença de Chagas? Disponível em: https://www.dndial.org/Doencas/Doenca-Chagas. Acesso em: 15 maio 2019.

EPSTEIN, Lee; KING, Gary. Pesquisa Empírica em Direito: as regras de inferência. São Paulo: Direito GV, 2013. Disponivel em: http://bibliotecadigital.fgv.br/dspace/handle/10438/11444. Acesso em: 29 maio 2019.

FERES, Marcos Vinício Chein. Direito Econômico: uma proposição teóricometodológica. Revista da Faculdade de Direito da UFJF - Tabulae, Juiz de Fora, v. 21, p. 31-45, 2004.

FERES, Marcos Vinício Chein; SILVA, Alan Rossi. A aspiração do sistema de patentes e o caso dos produtos terapêuticos para doenças negligenciadas. Revista Estudos Institucionais, Rio de Janeiro, v. 2, n. 2, p. 756-798, 1 fev. 2017. Disponível em: https://www.estudosinstitucionais.com/REI/article/view/60/115. Acesso em: 9 jul. 2019.

FERES, Marcos Vinício Chein; SILVA, Lorena Abbas da. Doença de Chagas e Patentes Farmacêuticas: pesquisa exploratória sobre a aspiração do sistema de patentes. Revista Estudos Institucionais, Rio de Janeiro, v. 4, n. 1, p. 278-307, 5 ago. 2018. Disponível em: https://estudosinstitucionais.com/REI/article/view/219. Acesso em: 15 maio 2020.

INSTITUTO BRASILEIRO DE GEOGRAFIA E ESTATÍSTICA - IBGE. Comissão Nacional de Classificação. 2019. Disponível em: https://concla.ibge.gov.br/buscaonline-cnae.html?subclasse=7210000\&view=subclasse. Acesso em: 10 jul. 2020.

INSTITUTO NACIONAL DA PROPRIEDADE INDUSTRIAL - INPI. Página Inicial. 2019. Disponível em: http://antigo.inpi.gov.br/. Acesso em: 15 maio 2019.

INSTITUTO NACIONAL DE PROPRIEDADE INDUSTRIAL - INPI. Resolução n ${ }^{\circ}$ 77, de 18 de março de 2013. Disciplina os procedimentos para a entrada na fase nacional dos pedidos internacionais de patente depositados nos termos do Tratado de Cooperação em Matéria de Patentes (PCT), junto ao INPI, como Organismo Designado ou Eleito, de forma a adequar tais pedidos às disposições da Lei de Propriedade Industrial - Lei no 9.279, de 14 de maio de 1996 (LPI). Disponível em: https://www.gov.br/inpi/pt-br/backup/legislacao-arquivo/docs/resolucao_77-2013.pdf. Acesso em: 1 ago. 2020. 
INSTITUTO NACIONAL DE PROPRIEDADE INDUSTRIAL - INPI. Resolução $\mathbf{n}^{\mathbf{o}}$ 217 , de 3 de maio de 2018. Disciplina a priorização do exame de pedidos de patente e patentes de produtos e processos farmacêuticos, bem como equipamentos e materiais relacionados à saúde pública. Disponível em: file://C:/Users/Anderson/Downloads/Resoluo2172018Republicao\%20(5).pdf.

Acesso em: 1 ago. 2020.

INTERFARMA. Guia 2019. Associação da Indústria Farmacêuticas de Pesquisa. Disponível em: https://www.interfarma.org.br/public/files/biblioteca/guia-interfarma2019-interfarma2.pdf. Acesso em: 16 fev. 2021.

KLEIN, H. E.; HASENCLEVER, L.; MACHADO, C. J. S. Regulação e difusão de tecnologias e sua influência na capacitação tecnológica em saúde dos países em desenvolvimento. Revista Brasileira de Ciência, Tecnologia e Sociedade, v. 2, n. 2, p. 130-149, jul./dez. 2011.

KOLliNG, Jacobi G.; DELGADO, Joedson. Direito à saúde, assistência médicohospitalar e mercado. Revista Direito Público, Brasília, v. 17, n. 93, p. 134-158, maio/jun. 2020.2 Disponível em: https://www.portaldeperiodicos.idp.edu.br/direitopublico/article/view/3079. Acesso em: 30 set. 2020 .

LEÃO, R.; GIESTERIA, L. F. O complexo industrial da saúde na Pintec 2017. Rio de Janeiro: Ipea, 2020 (Nota Técnica DISET n. 62). Disponível em: https://www.ipea.gov.br/portal/index.php?option=com_content $\&$ view=article $\&$ id $=355$ 70. Acesso em: 20 out. 2020.

MÉDECINS SANS FRONTIÈRES (Switzerland). Overcoming neglect: finding ways to manage and control ntds. Finding ways to manage and control NTDs. 2021. Disponível em: https://www.msf.org/overcoming-neglect-report-ntds. Acesso em: 20 fev. 2021.

MELCHOR, Paulo. O que é associação sem fins lucrativos? Disponível em: https://www2.unifap.br/mariomendonca/files/2011/05/ASSOCIA\%C3\%87\%C3\%83 O-SEM-FINS-LUCRATIVOS-INF.pdf. Acesso em: 12 jul. 2019.

ORGANIZAÇÃO DAS NAÇÕES UNIDAS- ONU. Resolução 41/128 da Assembleia Geral das Nações Unidas, de 4 de dezembro de 1986. Nova York, 1986. Disponível em: http://www.direitoshumanos.usp.br/index.php/Direito-aoDesenvolvimento/declaracao

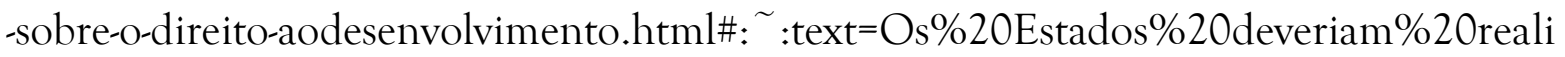
zar\%20seus,a\%20realiza\%C3\%A7\%C3\%A3o\%20dos\%20direitos\%20humanos. Acesso em: 10 jul. 2020.

OLIVEIRA, Egléubia Andrade de; LABRA, Maria Eliana; BERMUDEZ, Jorge. A produção pública de medicamentos no Brasil: uma visão geral. Cadernos de Saúde 
Pública, v. 22, n. 11, p. 2379-2389, nov. 2006. Disponível em: https://www.scielo.br/pdf/csp/v22n11/12.pdf. Acesso em: 12 jul. 2019.

PALUMA, Thiago; TEIXEIRA, Eline Débora. O marco legal da inovação e o aumento da interação entre universidade e empresa: contribuições para a consolidação do direito fundamental ao desenvolvimento. Revista Brasileira de Políticas Públicas, Brasília, v. 9, n. $1, \quad$ p. 352-371, abr. 2019. Disponível em: https://www.publicacoesacademicas.uniceub.br/RBPP/article/view/5622/pdf. Acesso em: 10 jul. 2020.

PARANHOS, J.; MERCADANTE, E.; HASENCLEVER, L. Os esforços inovativos das grandes empresas farmacêuticas no Brasil: o que mudou nas duas últimas décadas?. Revista Brasileira de Inovação, Campinas, SP, v. 19, p. e0200015, 2020. DOI: 10.20396/rbi.v19i0.8655780. Disponível em: https://periodicos.sbu.unicamp.br/ojs/index.php/rbi/article/view/8655780. Acesso em: 13 fev. 2021.

PONTES, Carlos Eduardo Collazo. Patentes de medicamentos e a indústria farmacêutica nacional: estudo dos depósitos feitos no Brasil. Revista Produção e Desenvolvimento, v. 3, n. 2, p. 38-51, 1 ago. 2017. Disponível em: https://revistas.cefetrj.br/index.php/producaoedesenvolvimento/article/view/e213. Acesso em: 10 set. 2020

RAUEN, Cristiane Vianna. O novo marco legal da inovação no Brasil: o que muda na relação ICT-empresa? Radar, Brasília, n. 43, p. 21-35, fev. 2016. Disponível em: https://www.ipea.gov.br/portal/images/stories/PDFs/radar/160309_radar43_cap_3.pd f. Acesso em: 10 set. 2020.

SALES, Matheus Vinícius Lage; QUEIROZ, Gustavo Lemes de. Os Instrumentos de Estímulo à Inovação nas Empresas trazidos pela Lei no 13.243/2016 e seu Comparativo com a Lei Mineira. In: SOARES, Fabiana de Menezes; PRETE, Esther Külkamp Eyng (org.). Marco Regulatório em Ciência, Tecnologia e Inovação: texto e contexto da Lei no 13.243/2016. Belo Horizonte: Arraes Editores, 2018. p. 1-222. Disponível em: http://www.fundep.ufmg.br/wp-content/uploads/2018/09/Livro_MARCO_REGULA TORIO_EM_CIENCIA_TECNOLOGIA_E_INOVACAO.pdf. Acesso em: 10 set. 2020.

SOUZA, Washington Peluso Albino de. Primeiras linhas de direito econômico. 4. ed. São Paulo: LTr, 1999.

VAZ, Isabel. Direito Econômico das Propriedades. Rio de Janeiro: Forense, 1992.

WORLD HEALTH ORGANIZATION. Neglected tropical diseases. 2018. Disponível em: http://www.who.int/neglected_diseases/diseases/en/. Acesso em: 20 jun. 2019. 
NOTA

Declaramos que o artigo intitulado "A POLÍTICA DE PATENTES ESTIMULA A INOVACุÃO? - O CASO DA DOENÇA DE CHAGAS”, submetido à Revista Opinião Jurídica, representa fruto direto das pesquisas desenvolvidas pelos autores, sobretudo no âmbito das atividades do projeto de pesquisa "Direito como identidade: direito à patente e o caso das drogas para doenças negligenciadas", tendo ambos realizado, concomitantemente, as tarefas de seu planejamento, execução e revisão da seguinte forma: 1) Marcos Vinício Chein Feres: Fundamentação teórico-conceitual, design metodológico, redação do texto e revisão final; 2) Anderson Resende Morais: Seleção de referências, fichamentos e redação do texto; 3) Andressa Mendes de Souza: Coleta e análise dos dados, fichamentos e redação do texto.

Por ser verdade, firmamos a presente em Juiz de Fora/MG, em 15 de fevereiro de 2021.

Como citar este documento:

FERES, Marcos Vinício Chein; MORAIS, Anderson Resende; SOUZA, Andressa Mendes de. A política de patentes estimula a inovação? - o caso da doença de Chagas. Revista Opinião Jurídica, Fortaleza, v. 19, n. 32, p. 58-84, set./dez. 2021. 